Voix et Images

voixetimages

\title{
Une si belle entrée, un si beau départ, Robert...
}

\section{Bernard Andrès}

Volume 13, numéro 2 (38), hiver 1988

Le propre du corps Roger Des Roches

URI : https://id.erudit.org/iderudit/200719ar

DOI : https://doi.org/10.7202/200719ar

Aller au sommaire du numéro

\section{Éditeur(s)}

Université du Québec à Montréal

\section{ISSN}

0318-9201 (imprimé)

1705-933X (numérique)

Découvrir la revue

\section{Citer cet article}

Andrès, B. (1988). Une si belle entrée, un si beau départ, Robert... Voix et Images, 13(2), 344-346. https://doi.org/10.7202/200719ar d'utilisation que vous pouvez consulter en ligne.

https://apropos.erudit.org/fr/usagers/politique-dutilisation/ 


\section{Une si belle entrée, un si beau départ, Robert...}

\section{par Bernard Andrès, Université du Québec à Montréal}

Robert Saint-Amour n'aura pas assisté au lancement de son premier roman. À quelques semaines près, il aurait encore pu apprécier cette illustration de Philippe Béha qui orne la couverture de Visiteurs d'hier ${ }^{1}$ : un petit homme bleu nous tire sa révérence, flanqué d'un chien volant, pattes roses, museau blanc. Plus de sept ans qu'il travaillait sur cet ouvrage à mi-chemin entre l'autobiographie et le bilan d'une époque. L'imagination, les mots, l'écriture: le dernier geste auquel se raccrocher quand le corps fout le camp. Et le pays. Et... Autant de thèmes qui hantent ce roman poli comme un galet. Un texte poli, oui: lisse et urbain, malgré les coups de gueule, les coups de sang, les quintes de toux et la révolte à peine contenue qui scandent le texte. Car rien ne transpire du travail, de la torture et des sueurs qu'auront valu à Saint-Amour les derniers mois de mise au point du manuscrit. C'est sur son lit d'hôpital, ou en convalescence, entre deux rechutes, profitant de chacun des répits que lui laissait le mal, que Robert s'acharnait à revoir et améliorer son texte. Quelle que soit notre méfiance à l'égard des parallèles trop commodes entre l'homme et l'œuvre, on ne peut que songer au véritable patient, à qui le médecin de garde assène, tout infatué de son jeune savoir: C'est le plus beau cas de pneumonie de ma carrière, puis: Vous avez attrapé votre coup de mort, mon cher monsieur. Et de nous rappeler semblables témoignages rapportés voilà si peu - car combien sont-ils à nous avoir quittés soudain ces derniers mois: André Belleau, Suzanne Lamy, René Payant? -: l'institution médicale et ses patients !.. Muets, pour la plupart, face à la mort et au pouvoir. Mais certains parlent, encore vivants, bien sûr, comme le note Pierre Hébert dans sa propre chronique. Saint-Amour en était. Mais dans son cas, la mort n'était guère un sujet qu'il aurait pris parmi tant d'autres. Plus que tout autre, il était pris par son sujet, dans un rapport antagonique géré par la PEUR.

Oui, J'AI EU PEUR. Si j'affirmais le contraire, je mentirais. Est-il pensable que dans le cours de sa vie, un homme ne rencontre pas la peur un jour? La "vraie»... La vraie qui est silencieuse, sournoise, sauvage, hargneuse [...] Lorsqu'elle surgit, elle ouvre la peau comme si elle fendait sous l'effet d'un violent coup de fouet... Vous avez attrapé votre coup de mort... Alors, au plus profond de soi, même si personne ne le voit, s'engage entre elle et nous une lutte d finir. Il faut la mater, sinon on est cuit... On s'attache à la vie comme un chien défend son os. Jusqu'à ce que le ventre se torde de douleur... (p. 20)

M. Vervet ne manque pas de formules pour caractériser sa petite personne: technocrate au mitan de sa quarantaine, il se désigne lui-même sans complaisance aucune, comme un masturbateur alité (p. 130), fils ingrat, mari frustré, père incestueux (p. 97). Au début du récit, le narrateur se retrouve à la maison depuis 
une semaine, après dix-huit jours d'hospitalisation. Pleuropneumonie bilatérale en régression, mais hantise des quintes de toux qui lui labourent le thorax. Fort diminué physiquement, alité ou, dans le meilleur des cas, traînant dans l'appartement, ses contacts sont limités aux visites d'Any, son amie, de ses enfants, Brigitte et Arnaud, de quelques rares amis, de Mme Latraverse, la femme de ménage, du voisinage de Mme Veilleux... et de Crique, la chatte. C'est par le truchement de ces personnages que Vervet (qui ne manque pas de... bagout) communique avec l'extérieur, tente de se remémorer, par-delà l'hospitalisation, le détail d'une existence peu exaltante. Mis à part sa vie professionnelle, Vervet n'a connu que des déboires: familiaux, sentimentaux, conjugaux, sexuels (surtout?), mais aussi idéologiques. L'échec du nationalisme (tout se joue autour du référendum) anime la plupart des réflexions du narrateur. Et pourtant, cet amoncellement de frustrations ne se fait nullement sur le registre de la jérémiade ou sur le ton désabusé de la «Bof génération» évoquée par Pierre Hébert. Subsistent chez Vervet, outre un humour à la Hasek (toujours savoureux, parfois décapant lorsqu'il s'agit de fustiger l'Hôpital), une confiance inébranlable dans la nature humaine et dans sa capacité à surmonter l'adversité. Non sans quelque perversité quand le patient de Maisonneuve parvient à reprendre le dessus dans les pires conditions d' «internement» et malgré les mauvais traitements que lui fait subir le personnel dit «hospitalier». Comme chez le Brave Soldat Zwejk, la satire confine alors au pamphlet:

Les corridors sont comblés de civières qui s'alignent a la queue leu leu [...] Partout, des corps humains qui, parqués là, souffrent, dorment, mangent, attendent, pissent et chient publiquement. Un abattoir n'est pas plus triste, pas plus poignant. Quel dégoûtant théâtre de l'exhibitionnisme institutionnalisé! J'ai observé des médecins qui auscultaient sans vergogne, au vu et au su de tout le monde, le ventre blanc et marbré d'une jeune femme enceinte... une sorte de viol fait sur la place publique [...] et je me suis senti lâche d'assister à cette scène en voyeur sans la dénoncer, sans manifester mon indignation... Mais en avoir eu le courage, j'aurais tout le matériel pour un pamphlet percutant... (p. 189)

Ce qui sauve toutefois le récit de ces tentations pamphlétaires, c'est un certain code herméneutique sur lequel nous reviendrons, ainsi que la dimension humaine, profondément ouverte aux autres, de l'univers de Vervet. De son enfance inquiète, bercée par la vision de sa tante dénudée, par l'aura du père Dastoux (père spirituel, pour le moins), de ses premiers émois érotiques à ses dernières amours déçues, Vervet garde une foi solide dans les êtres qu'il côtoie et dans les principes (idéologiques, moraux) qui guident sa conduite, ou qu'il transgresse à l'occasion. Même ces femmes qui l'intriguent, le dépossèdent (de ses enfants, de sa sexualité), qu'il fantasme de violenter, elles fonctionnent dans le roman comme ses compagnes d'infortune. C'est d'ailleurs grâce à l'une d'entre elles (sa tante Vivianne) qu'il percera le secret de sa propre mère et par là même l'intrigue du passant de 9 heures qui le saluait quotidiennement et dont la figure énigmatique traverse tout le récit. Car, alors que le père semble cruellement faire 
défaut dans cette modeste famille du quartier Maisonneuve, le roman met tôt en place une série d'indices convergeant vers une autre figure. Discrètement, par touches successives, celle-ci finit par miner le récit en subsumant tous les autres niveaux d'interprétation. Et le prodige de ce roman réside sans doute dans la façon dont il parvient à donner sens et consistance à toute une myriade de petits faits vécus dont aucun, pris isolément, ne suffirait à capter l'attention, mais dont la constellation savamment ouvragée, finit par séduire le lecteur.

Dans l'espace des trente dernières pages, tout le réseau ainsi tissé, toutes les coïncidences éparses du récit convergent vers un point précis dont on découvre, ravi, qu'il régentait l'ensemble: l'identité révélée du promeneur de 9 heures. Et comme au terme d'une hasardeuse recherche du temps perdu, mais sans l'aplomb du narrateur-inspecteur assenant LA réponse, Saint-Amour/Vervet renonce à convoquer ses personnages. Ne semble-t-il pas surpris lui-même d'avoir percé l'énigme? La confrontation spectaculaire n'aura pas lieu.

[...] à quoi bon? C'est comme si j'avais craint que de nouveaux propos ne viennent ternir la beauté et la douleur réveillées par la spontanéité des souvenirs rappelés dans ce journal... C'est comme si j'avais craint que tous ces instants merveilleux et difficiles, pénibles et agréables, ne se fussent à jamais déformés au contact de la réalité... (p. 244)

Et le narrateur de se retirer sur la pointe des pieds, déguisant son départ comme il avait soigné son arrivée dans nos lettres:

Voilà pourquoi il m'a semblé préférable de garder confiné à ces seules pages le souvenir de mes rencontres avec mes visiteurs d'hier.

s'éclipsant comme le petit homme bleu sur la couverture: sans prendre le temps de nous donner sa pleine mesure, avec cette bonhomie désarmante qui caractérisa Robert jusqu'au dernier moment, au dernier souffle, lorsqu'il nous disait: «Ne restez pas trop longtemps, ça me fatigue. Venez plus souvent. Et puis, on se reverra au lancement...»

1 Robert Saint-Amour, Visiteurs d'hler, Québec/Amérique, 1987, 244 p. Les références ultérieures se feront par la simple mention du numéro de page entre parenthèses. 